\title{
Low-Voltage DC Input, High-Voltage Pulse Generator Using Nano-Crystalline Transformer and Sequentially Charged MMC Sub-modules, for Water Treatment Applications
}

\author{
M. A. Elgenedy ${ }^{1}$, A. M. Massoud ${ }^{2}$, D. Holliday ${ }^{1}$, S. Ahmed ${ }^{3}$ and B.Williams ${ }^{1}$ \\ ${ }^{1}$ University of Strathclyde, Glasgow, UK. \\ ${ }^{2}$ Qatar University, Doha, Qatar. \\ ${ }^{3}$ Texas A\&M University at Qatar, Doha, Qatar. \\ mohamed.elgenedy@strath.ac.uk
}

\begin{abstract}
This paper proposes a new high-voltage Pulse Generator (PG), fed from low voltage dc supply $V_{s}$. This input supply voltage is utilized to charge two arms of $N$ series-connected modular multilevel converter sub-module capacitors sequentially through a resistive-inductive branch, such that each arm is charged to $\boldsymbol{N} V_{s}$. With a step-up nano-crystalline transformer of $n$ turns ratio, the proposed $P G$ is able to generate bipolar rectangular pulses of peak $\pm n N V_{s}$, at high repetition rates. However, equal voltage-second area of consecutive pulse pair polarities should be assured to avoid transformer saturation. Not only symmetrical pulses can be generated, but also asymmetrical pulses with equal voltage-second areas are possible. The proposed topology is tested via simulations and a scaled-down experimentation, which establish the viability of the topology for water treatment applications.
\end{abstract}

Keywords-Pulse generator; Modular Multilevel Converter (MMC); nano-crystalline transformer; bipolar pulses; rectangular pulse-waveform

\section{INTRODUCTION}

The disinfection process in water treatment is a crucial step before piping the water to homes and businesses. Usually, it takes place after filtration, where a disinfectant (for example chlorine, and chloramine) is added to the water. The disinfection process aims to kill any remaining parasites, bacteria, and viruses to protect the water from germs before its piping [1]. Alternatively, disinfection can be successfully achieved by applying lethal electroporation to the water under treatment [2]. Generally, electroporation is the process of applying HighVoltage (HV) pulses, a Pulsed Electric Field (PEF), across a biological cell membrane. If the electric field is higher than the critical field that the cell membrane can withstand, the cell dies and the electroporation is lethal. Otherwise, the electroporation is non-lethal [2]. Lethal electroporation is utilized in several applications, such as water treatment, air pollution control, food sterilization and tissues ablation in medical applications [3]. In contrast, non-lethal electroporation is utilized, for example, in bio-fouling in industrial applications and protein insertion in medical applications [3].

This work was supported by a National Priorities Research Program (NPRP) grant NPRP (7-203-2-097) from the Qatar National Research Fund (QNRF)
HV Pulse Generators (PGs) have been utilized in electroporation applications. They vary from classical generators, such as Marx generator and pulse forming networks, to modern power electronics-based generators [2]. Generally, classical PGs generate HV pulses with limited flexibility and low repetition rates. However, employing power electronic switches with their later developments (such as high voltage withstand and high switching frequency operation) has led the emergence of new HV PG topologies. Modular Multilevel Converter (MMC) Sub-Modules (SMs) are utilized in modern PGs to afford redundancy, scalability and modularity [4]-[8]. Usually, MMC-based PG topologies are fed from a HVDC input $\left(V_{d c}\right)$, as in HVDC transmission applications, and the novelty of these emerged MMC PG topologies focused on the concept of generating the $\mathrm{HV}$ pulses with flexible pulse shapes, whilst assuring individual voltage balance of each SM capacitor with reduced (or no) capacitor voltage measurements [4]-[6]. Accordingly, the maximum peak voltage of the generated pulses is $\pm V_{d c}$, if four MMC arms form an H-bridge as in [6], or $\pm \frac{1}{2} V_{d c}$ if two MMC arms are utilized as in [4]-[5].

Sequential charging of the individual series-connected HalfBridge (HB)-MMC SM capacitors through resistors from a Low Voltage dc (LVDC) supply is proposed in [7] to generate unipolar rectangular pulses. In [8] the sequential topology of [7] is modified by using full-bridge SMs to generate bipolar pulses.

This paper proposes a new PG topology fed from LVDC supply and generates HV bipolar rectangular pulses. The proposed PG is formed of two parallel phase-legs, one leg is responsible of positive pulse generation while the other leg generates a negative pulse polarity. Each phase-leg contains two arms, the upper arm is formed of series connected HB-MMC $\mathrm{SMs}$, while the lower arm is formed of series-connected reverse blocking switches. The SM capacitors are charged sequentially from the LVDC supply through a resistive-inductive $(r L)$ branch such that the input charging current has a slightly under damped response which allows rapid sequential charging of the SM capacitors. The sequentially-charged SM-capacitors are inserted simultaneously during pulse generation, hence the peak pulse voltage is $\pm N V_{s}$. The formed bipolar pulses are applied 
across the load through a step-up nano-crystalline core based transformer with $n$ turns ratio. Accordingly, the generated pulses have a peak voltage of $\pm n N V_{s}$ as a result of the double magnification.

The validity of the proposed topology is assessed via Matlab/Simulink simulations and scaled-down experimentation. The obtained results validate the proposed topology for water treatment applications. The proposed PG topology is introduced in section II, along with its operation principle. Simulation and experimental results are present in sections III and IV, respectively. Finally, section V outlines the conclusions.

\section{PROPOSED TOPOLOGY PRINCIPLE OF OPERATION}

The proposed PG topology is shown in Fig. 1. The upper arms, Arm1 and Arm2, are formed of $N$ series-connected HBMMC SMs which are charged sequentially from the LVDC supply $V_{S}$ through an $r L$ branch via reverse blocking switches $S_{1}$ and $S_{2}$ respectively. During charging of a particular arm SM capacitors, the other arm SMs are idled. The SM capacitors of the charging arm are charged sequentially by bypassing the other series SMs in the arm while inserting the charging SM capacitor. The operating sequence of the topology to generate bipolar rectangular pulses, shown in Fig. 2, is illustrated in Table I. The pulse generation is formed of four stages, consecutively, the positive pulse, the positive SM capacitors charging, the negative pulse, and the negative SM capacitors charging.

The formed voltage pulse $\left(V_{t}\right)$ across the primary winding of the transformer is stepped up by transformer turns ratio $n$ before being applied across the load. Hence, the generated voltage pulse $\left(V_{L}\right)$ is magnified by the number of $N$ sequentially charged SMs as well as the transformer turns ratio $n$ yielding to a voltage pulse of peak $\pm n N V_{s}$ across the load. By varying the number of MMC cells in-circuit, up to $N$ cells, output pulse shaping is possible.

Reverse blocking semi-conductor switches are required for $S_{1}$ and $S_{2}$ which can comprise an IGBT in series with a diode, as shown in Fig. 1. This is because during pulse generation, $S_{1}$ and $S_{2}$ arms are OFF and a reverse voltage of $(N-1) V_{s}$ is applied across them. The rating of the IGBT switch is $V_{s}$, and since an LVDC input source is used, a single IGBT should be sufficient. Additionally, Zero Voltage Switching (ZVS) is assured during IGBT turn ON/OFF, thus, series connection of IGBTs (if required) or the diode(s) should not present a sharing issue.

The nano-crystalline core material is preferred (over ferrite) for high-frequency operation due to its high core permeability, hence high magnetizing inductance, high flux density, and near square hysteresis loop [9]. The reduced transformer volume, due to high-frequency operation, enhances the modularity of the proposed topology. Bipolar rectangular voltage pulses are advantageous over unipolar rectangular pulses in terms of applying mechanical stresses to the sample under treatment in addition to electrical stresses [10]. Using a transformer in the proposed PG supports bipolar voltage pulse generation, however, two aspects should be considered namely: the leakage inductance of the transformer and the voltage-second balance.

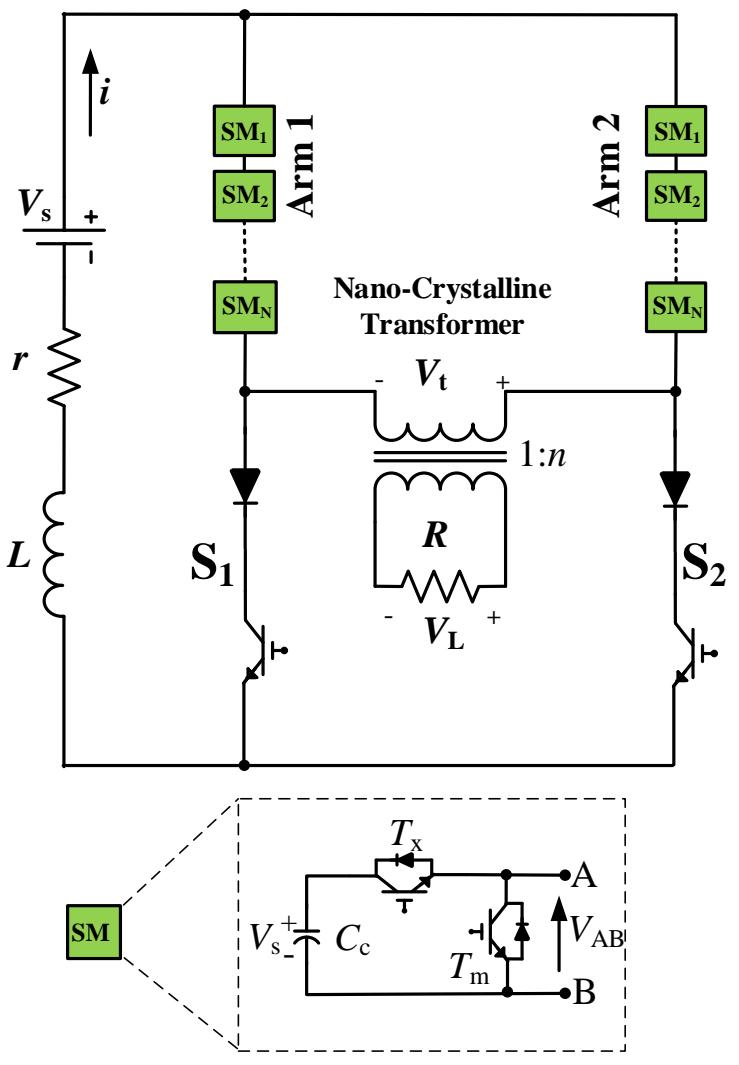

SM Switching States

\begin{tabular}{c|c|c}
\hline$T_{\mathrm{m}}$ & $T_{\mathrm{x}}$ & State \\
\hline $\mathrm{ON}$ & $\mathrm{OFF}$ & Bypassed \\
\hline OFF & $\mathrm{ON}$ & Inserted \\
\hline OFF & OFF & Idled \\
\hline
\end{tabular}

Fig. 1. Proposed PG topology.

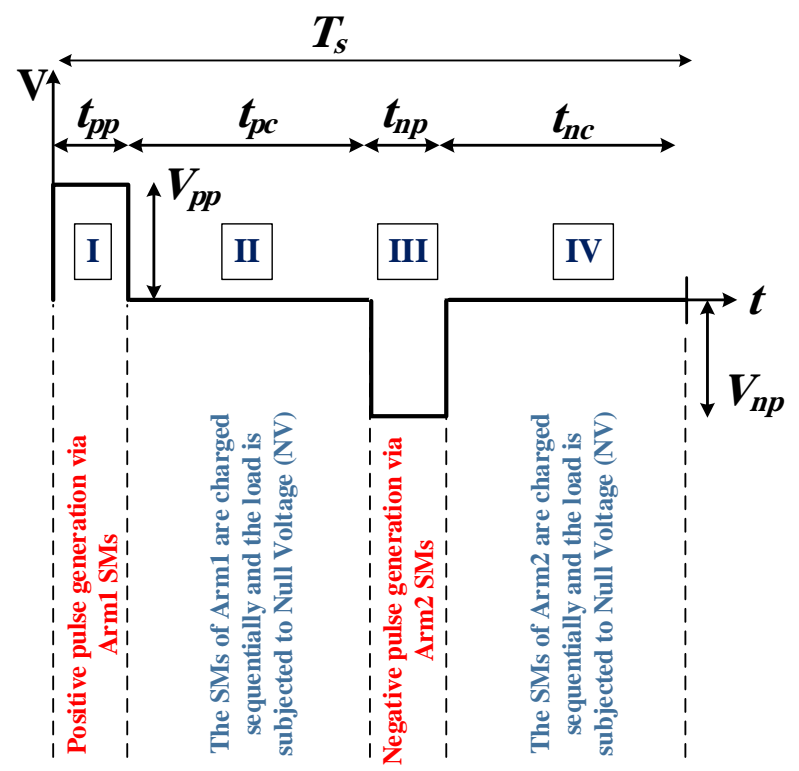

Fig. 2. Generated bipolar rectangular voltage pulse across the transformer primary. 
TABLE I

SEQUENCE OF OPERATION AND CIRCUIT CONFIGURATION DURING THE GENERATION OF A COMPLETE BIPOLAR PULSE CYCLE

\begin{tabular}{|c|c|c|c|c|}
\hline & Positive Pulse & Positive arm SMs charging & Negative Pulse & Negative arm SMs charging \\
\hline 苞 & (I) & 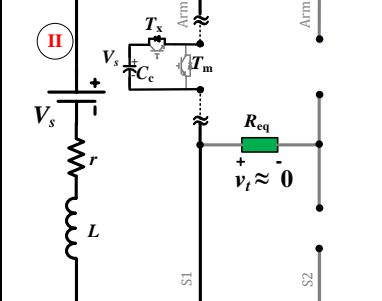 & $C_{-v_{\mathrm{t}}^{-}}^{C_{c} / N}$ & IV \\
\hline 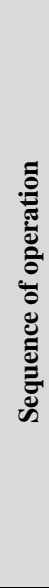 & $\begin{array}{l}\text { - } \mathrm{S}_{1} \text { and } \mathrm{S}_{2} \text { switches are } \\
\text { OFF. } \\
\text { - Arm2 SMs are bypassed to } \\
\text { provide a path for Arm1 } \\
\text { discharging } \\
\text { capacitors. } \\
\text { - A Positive pulse of voltage } \\
\text { peak } V_{p p} \text { is formed across } \\
\text { the transformer primary } \\
\text { for a duration of } t_{p p} \text {. }\end{array}$ & $\begin{array}{l}\text { - } \mathrm{S}_{1} \text { is ON (while charging SM } \\
\text { capacitors of Arm1) and } \mathrm{S}_{2} \text { is } \\
\text { OFF. } \\
\text { - Arm1 SM capacitors are } \\
\text { inserted sequentially to re- } \\
\text { charge Arm1 SM capacitors, } \\
\text { each to } \mathrm{V}_{\mathrm{s}} \text {. } \\
\text { - All Arm } 2 \mathrm{SMs} \text { are idle* } \\
\text { - To charge SMs of Arm1, the } \\
\text { first charging SM is inserted, } \\
\text { then } \mathrm{S}_{1} \text { is turned ON (hence, it } \\
\text { has ZVS). } \\
\text { - After charging the last SM, } \mathrm{S}_{1} \\
\text { is turned OFF safely since the } \\
\text { charging current is zero. } \\
\text { - During Arm1 SMs charging } \\
\text { duration } t_{p c} \text { the transformer } \\
\text { primary voltage is nullified. }\end{array}$ & $\begin{array}{l}\text { - } \mathrm{S}_{1} \text { and } \mathrm{S}_{2} \text { switches are OFF. } \\
\text { - Arm1 SMs are bypassed to } \\
\text { provide a path for Arm } 2 \\
\text { discharging SM capacitors. } \\
\text { - Negative pulse } V_{n p} \text { is formed } \\
\text { across the transformer primary } \\
\text { for a duration of } t_{n p} \text {. }\end{array}$ & $\begin{array}{l}\text { - } \mathrm{S}_{1} \text { is OFF and } \mathrm{S}_{2} \text { is ON (while } \\
\text { charging SM capacitors of } \\
\text { Arm2). } \\
\text { - Arm2 SM capacitors are } \\
\text { inserted sequentially to re- } \\
\text { charge the individual Arm2 SM } \\
\text { capacitors to } \mathrm{V}_{\mathrm{s}} \text {. } \\
\text { - All Arm1 SMs are idle* } \\
\text { - To allow charging the SMs of } \\
\text { Arm2, the first charging SM is } \\
\text { inserted, then } \mathrm{S}_{2} \text { is turned ON } \\
\text { (hence, it has ZVS). } \\
\text { - After charging the last SM, } \mathrm{S}_{2} \\
\text { turns OFF safely since the } \\
\text { charging current is zero. } \\
\text { - During the Arm2 SMs charging } \\
\text { duration } t_{n c} \text { the transformer } \\
\text { primary voltage is nullified. }\end{array}$ \\
\hline
\end{tabular}

The transformer leakage inductance limits the generated duration of the pulses, thus, the leakage should be measured in order to determine the allowable pulse duration range. Voltagesecond balance is assured for symmetrical bipolar pulses, however, asymmetrical pulses must maintain the voltagesecond balance (otherwise, the transformer core will accumulate flux and saturate). Thus, the following equation should be applied to determine the suitable pulse polarity magnitude and duration while assuring transformer voltagesecond balance

$$
V_{p p} t_{p p}=V_{n p} t_{n p}
$$

where, $V_{p p}$ and $V_{n p}$ are the peak of the positive and negative pulse polarities while $t_{p p}$ and $t_{n p}$ are the corresponding pulse polarity durations, respectively (assuming rectangular pulses). Effectively, the generated pulses should be in the kilo-volt magnitude range $(1-100 \mathrm{kV})$ with pulse durations between nanoseconds and milliseconds [10]; generally decreasing in duration as voltage increases. The water sample under treatment is modelled as an $R$ load when considering pulse durations of micro-seconds and above [11].

\section{Simulation Results}

The charging of the individual SM capacitors through the $r L$ branch is based on a slightly underdamped response of the $r L C_{c}$ circuit, hence, the SM capacitors have fast charging. Thus, the selection of $r L C_{c}$ values is made such that the capacitor voltage has a smaller drop [11] while the input charging current has an underdamped response, that is $C_{c}<\frac{4 L}{r^{2}}$. Accordingly, the SM capacitor size is calculated from [11],

$$
C_{c}=\frac{2 N t_{p l}}{\left(1-\beta^{2}\right) R}
$$

where $\beta$ is the percentage remaining voltage on the SM capacitor after pulse generation and $t_{p l}$ is the longest pulse polarity duration (i.e. the longest among $t_{p p}$ and $t_{n p}$ ). While the charging current is expressed as

$$
i(t)=\frac{\beta V_{s}}{\left(\sqrt{\frac{L}{C_{c}}-\frac{r^{2}}{4}}\right)} e^{-\frac{r}{2 L} t} \sin \sqrt{\frac{1}{L C_{c}}-\frac{r^{2}}{4 L^{2}}} t
$$

After re-charging the SM capacitor, the charging current is reduced to zero, $i\left(t_{c}\right)=0$, solving (3) for the charging time $t_{c}$ yields

$$
t_{c}=\frac{\pi}{\sqrt{\frac{1}{L C_{c}}-\frac{r^{2}}{4 L^{2}}}}
$$


The SM charging time, $t_{c}$, is the control variable to determine the maximum possible repetition time provided by the PG, where

$$
T_{s}=2 N t_{c}+t_{p p}+t_{n p}
$$

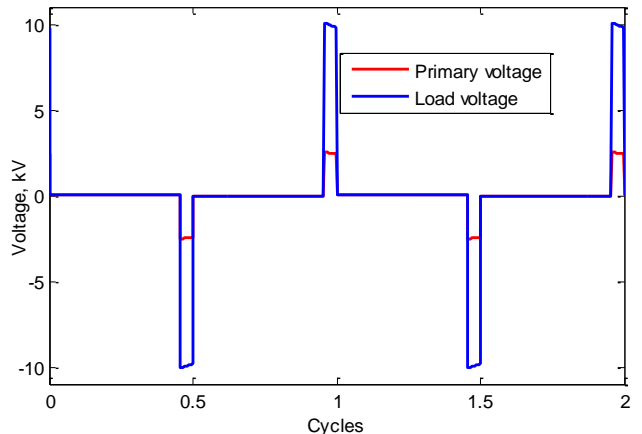

(a)

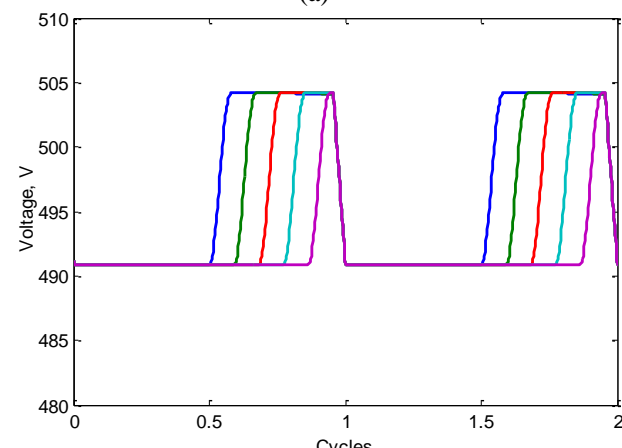

(b)

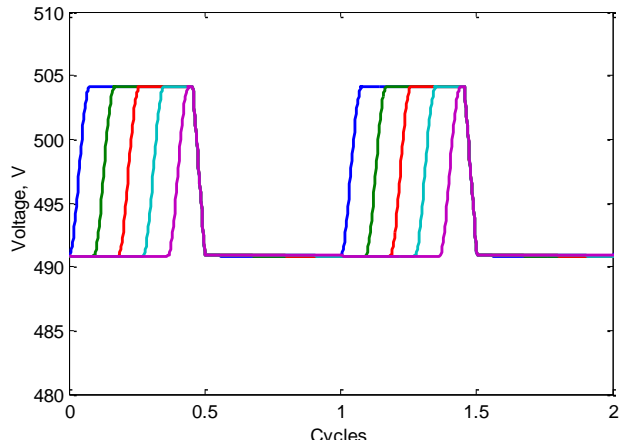

(c)

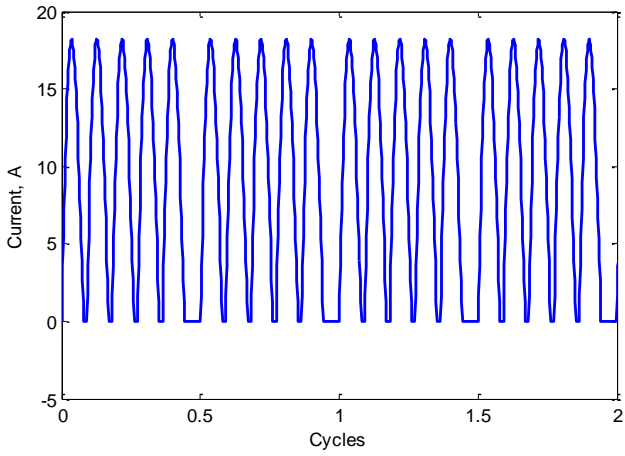

(d)

Fig. 3. Generation of $10 \mathrm{kV}$ peak, $10 \mu \mathrm{s}$ bipolar pulses. (a) Voltage pulses across the transformer primary and the load. (b) Five SM capacitor voltages of the negative pulse, Arm1. (c) Five SM capacitor voltages of the positive pulse, Arm2. (d) Input charging current of the SM capacitors.
TABLE II

SIMULATION AND EXPERIMENTAL SPECIFICATIONS

\begin{tabular}{|l|c|c|c|}
\hline \multicolumn{2}{|c|}{ Parameter } & Simulation & Experimental \\
\hline LVDC input voltage & $V_{s}$ & $500 \mathrm{~V}$ & $30 \mathrm{~V}$ \\
\hline Input inductance & $r L$ & $0.1 \Omega$ and $2 \mu \mathrm{H}$ & $0.5 \Omega$ and $5 \mu \mathrm{H}$ \\
\hline Number of SMs/arm & $N$ & 5 & 3 \\
\hline Transformer turns ratio & $n$ & 4 & 3 \\
\hline Load resistance & $R$ & $2 \mathrm{k} \Omega$ & $1 \mathrm{k} \Omega$ \\
\hline SM capacitance & $C_{c}$ & $10 \mu \mathrm{F}$ & $15 \mu \mathrm{F}$ \\
\hline SM charging time & $t_{c}$ & $14 \mu \mathrm{s}$ & $30 \mu \mathrm{s}$ \\
\hline Percent remaining voltage & $\beta$ & \multicolumn{2}{|c|}{$>0.95$} \\
\hline
\end{tabular}

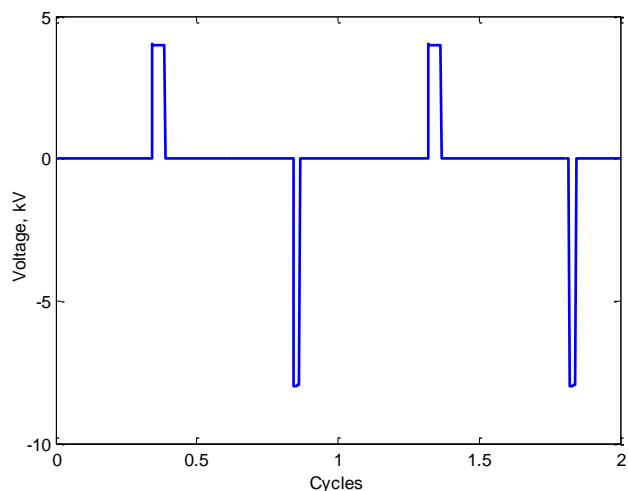

(a)

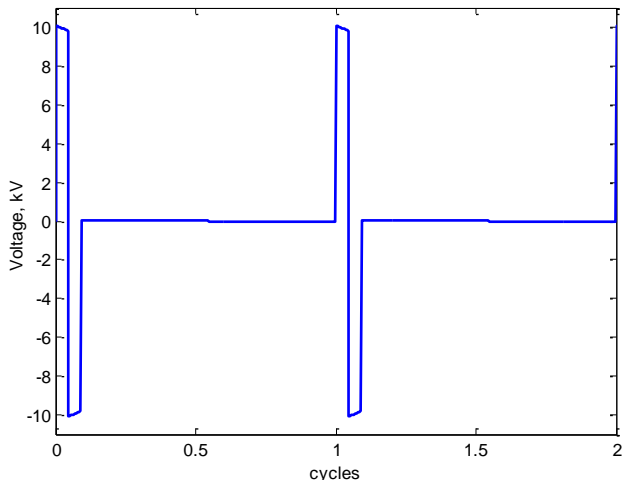

(b)

Fig. 4. Generation of different bipolar pulse shapes whilst ensuring the transformer voltage-second balance constraint. (a) Combined null-load voltage duration bipolar pulses of $10 \mu \mathrm{s}$ pulse durations and $10 \mathrm{kV}$ peak. (b) Asymmetric bipolar pulses of $10 \mu$ s positive-pulse duration and $4 \mathrm{kV}$ peak and $5 \mu$ s negative-pulse duration with $8 \mathrm{kV}$ peak.

Matlab/Simulink simulations are used to validate the proposed topology, with the specifications given in Table II. Bipolar rectangular pulses with positive and negative durations of $10 \mu \mathrm{s}$, voltage pulse peak of $10 \mathrm{kV}$ and repetition rate of $5 \mathrm{kHz}$ are shown in Fig. 3a. In Fig. 3a, the primary voltage of the transformer is $2.5 \mathrm{kV}$, which is the sum of the sequentially charged five SM capacitors, while the voltage across the load is $10 \mathrm{kV}$, since the transformer has $n=4$. The capacitor voltages of Arm 1 and Arm 2 are shown in Figs. $3 b$ and 3c, respectively, where each capacitor fluctuates around $500 \mathrm{~V}$, with a voltage ripple lesser than 5\%. 
The current flows from the LVDC supply to charge the individual SM capacitors during the charging period is shown in Fig. 3d. It can be seen that the current drops to zero after the SM capacitor re-charged to $500 \mathrm{~V}$ with charging time of $14 \mu \mathrm{s}$.

The flexibility of the proposed PG is explored by generating asymmetrical bipolar pulses and combined null-load voltage durations pulses as in Fig. 4. Fig. 4a shows asymmetric bipolar pulse with a positive polarity peak of $4 \mathrm{kV}$ and $10 \mu$ s duration, while the negative pulse polarity has an $8 \mathrm{kV}$ peak and $5 \mu \mathrm{s}$ duration. Moreover, combining the null-load voltage durations is explored in Fig. $4 \mathrm{~b}$ with $10 \mu \mathrm{s}$ pulse durations and $10 \mathrm{kV}$ peak voltage.

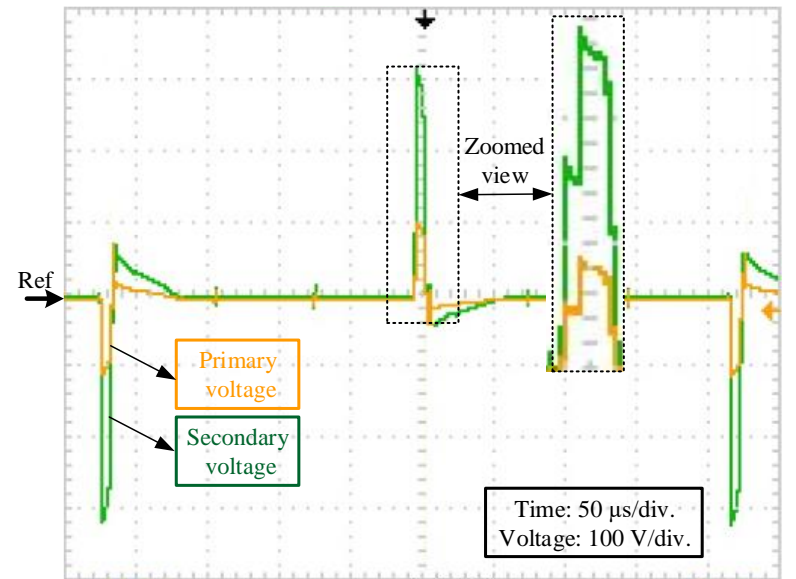

(a)

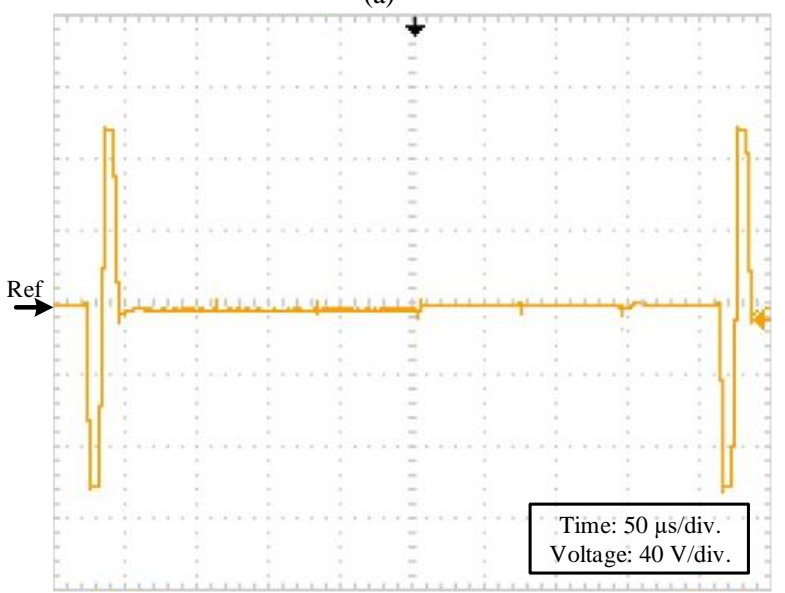

(c)

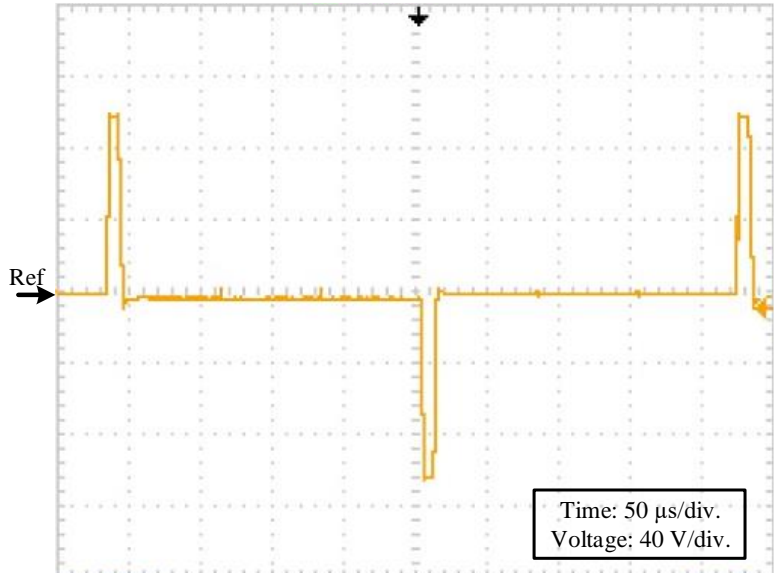

(b)

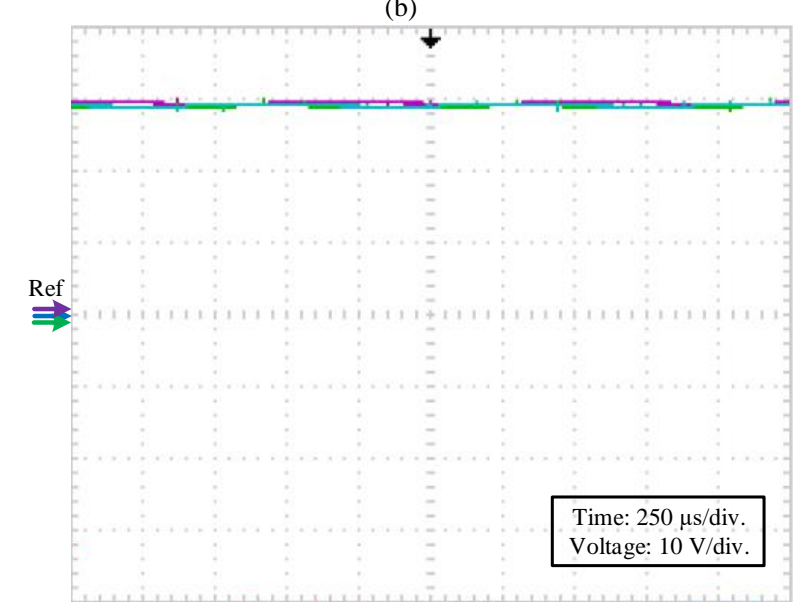

(d)

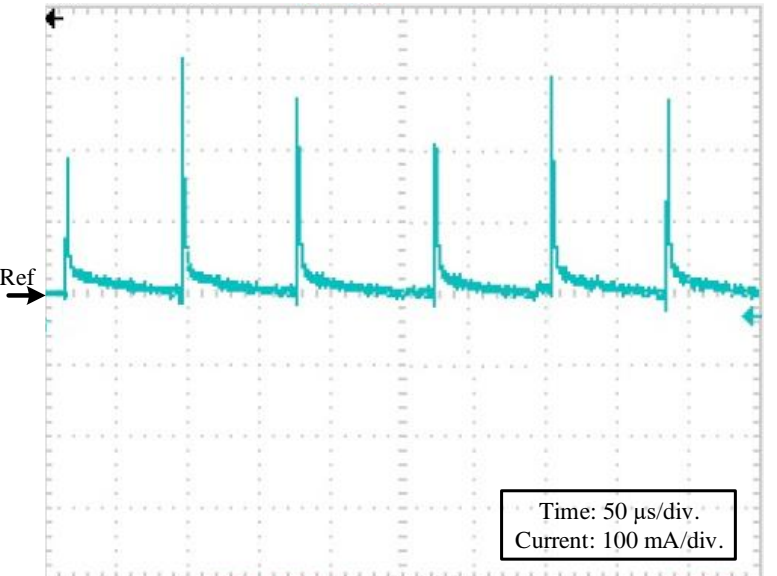

(e)

Fig. 5. Scaled-down experimental results of the proposed topology. (a) Primary and secondary voltage pulses of non-combined null-load voltage durations bipolar pulses. (b) Primary voltage pulses of non-combined null-load voltage durations bipolar pulses. (c) Primary voltage pulses of combined null-load voltage durations bipolar pulses. (d) Three individual SM capacitors voltage of Arm2. (e) Input charging current. 


\section{EXPERIMENTAL RESULTS}

Although transformer leakage inductance is ignored in the simulations, its effect is seen in the experimental validation. To minimize transformer leakage inductance, the primary turns are wound over the secondary windings. Its experimentallydeduced value from the secondary side leakage inductance $L_{l}$, which will be connected across the load, is $3.56 \mu \mathrm{H}$. Accordingly, for load resistance of $1 \mathrm{k} \Omega$, the generated pulse will require $\Delta t=L_{l} / R=3.56 \mathrm{~ns}$ for each polarity to reach the required peak value. Thus, for proper operation, the pulse polarity duration time should be larger than $\Delta t$. Consequently, microsecond pulse durations can be generated safely, which are targeted in this paper.

The primary and secondary voltages of bipolar pulses with pulse polarity duration of $10 \mu$ s and repetition time of $400 \mu \mathrm{s}$, are shown in Fig. 5a. The voltage-peak of the generated pulses across the load is $300 \mathrm{~V}$, since the transformer turns ratio is 3 and the primary voltage is $100 \mathrm{~V}$, as in Fig. 5a. The primary voltage of bipolar pulses with non-combined as well as combined null-load voltage durations and a peak voltage of 90V, are shown in Figs. 5b and 5c, respectively. Accordingly, each of the three individual SM capacitor voltages in the two MMC arms fluctuate around $33 \mathrm{~V}$ as shown for Arm2 SMcapacitors in Fig. 5d. Finally, the charging input current is shown in Fig. 5e for the pulses in Fig. 5a.

\section{CONCLUSION}

This paper presented a new PG topology to generate HV bipolar pulses for disinfection in water treatment applications. The proposed PG is based on HB-MMC SMs which provide modularity and scalability of the topology. The individual SM capacitors are charged sequentially through reverse blocking semiconductor switches and an $r L$ branch from a LVDC input supply. The selection of the $r L$ branch is such that, during the sequential charging of the SM capacitors, the charging current has an underdamped response, therefore the capacitors charge fast. A step-up nano-crystalline core based transformer, with low leakage inductance, is connected across the load for pulsevoltage magnification. The proposed topology was assessed via simulations and scaled-down experimentation, which established the viability of the topology for water treatment application.

\section{ACKNOWLEDGMENT}

This work was supported by the Qatar National Research Fund (a member of the Qatar Foundation) under NPRP Grant (7203-2-097). The statements made herein are solely the responsibility of the authors.

\section{REFERENCES}

[1] Water Treatment Manual: Disinfection, Office of Environmental Enforcement, Environmental Protection Agency-EPA, Wexford, Ireland, 2011.

[2] H. Bluhm, Pulsed power system: Principles and applications: Berlin: Springer, 2006.

[3] J. Raso and V. Heinz, Pulsed electric fields technology for the food industry: Fundamentals and applications: New York ; London : Springer, 2006.

[4] L. Lamy Rocha, J. F. Silva, and L. M. Redondo, "Multilevel high-voltage pulse generation based on a new modular solid-state switch," IEEE Trans. Plasma Sci., vol. 42, pp. 2956-2961, Oct. 2014.

[5] A. A. Elserougi, A. M. Massoud, and S. Ahmed, "Modular multileve converter-based bipolar high-voltage pulse generator with sensorless capacitor voltage balancing technique," IEEE Trans. Plasma Sci., vol. 44 pp. 1187-1194, 2016.

[6] M. A. Elgenedy, A. Darwish, S. Ahmed, and B. W. Williams, "A modular multilevel-based high-voltage pulse generator for water disinfection applications," IEEE Trans. Plasma Sci., vol. 44, pp. 2893-2900, 2016.

[7] A. A. Elserougi, A. M. Massoud, and S. Ahmed, "A modular high-voltage pulse-generator with sequential charging for water treatment applications," IEEE Trans. Ind. Electron., vol. 63, pp. 7898-7907, 2016.

[8] A. A. Elserougi, I. Abdelsalam, A. M. Massoud, and S. Ahmed, "A fullbridge submodule-based modular unipolar/bipolar high-voltage pulse generator with sequential charging of capacitors," IEEE Trans. Plasma Sci., vol. PP, pp. 1-9, 2016.

[9] B. W. Williams, Power Electronics: Devices, Drivers, Applications, and Passive Components. London, U.K.: Macmillan, 1992.

[10] K. H. Schoenbach, S. Katsuki, R. H. Stark, E. S. Buescher, and S. J. Beebe, "Bioelectrics-new applications for pulsed power technology," IEEE Trans. Plasma Sci., vol. 30, pp. 293-300, 2002.

[11] M. A. Elgenedy, A. Darwish, S. Ahmed, and B. W. Williams, "A transition arm modular multilevel universal pulse-waveform generator for electroporation applications," IEEE Trans. Power Electron., vol. PP, no. 99, pp. 1-1, 2017. 